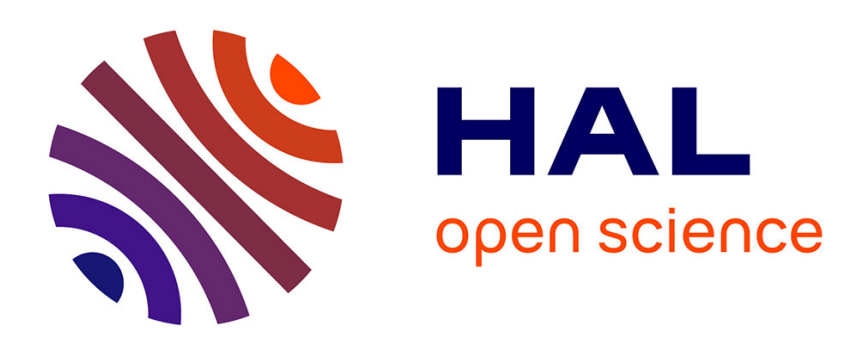

\title{
Creating Products in the Absence of Markets: A Robust Design Approach
}

Philippe Silberzahn, Christophe Midler

\section{To cite this version:}

Philippe Silberzahn, Christophe Midler. Creating Products in the Absence of Markets: A Robust Design Approach. International Journal of Manufacturing Technology and Management, 2007, pp.000. hal-00263305

\section{HAL Id: hal-00263305 \\ https://hal.science/hal-00263305}

Submitted on 10 Apr 2008

HAL is a multi-disciplinary open access archive for the deposit and dissemination of scientific research documents, whether they are published or not. The documents may come from teaching and research institutions in France or abroad, or from public or private research centers.
L'archive ouverte pluridisciplinaire HAL, est destinée au dépôt et à la diffusion de documents scientifiques de niveau recherche, publiés ou non, émanant des établissements d'enseignement et de recherche français ou étrangers, des laboratoires publics ou privés. 


\section{Creating Products in the Absence of Markets: A Robust Design Approach}

Philippe Silberzahn (1) and Christophe Midler (2)

(1) Ecole Polytechnique, France, and INSEAD, France
(2) Ecole Polytechnique, France

Word count: 6523 


\title{
Creating Products in the Absence of Markets: A Robust Design Approach
}

\begin{abstract}
Purpose - The purpose of this study is to examine how firms deal with a situation of true uncertainty about their potential markets and technologies. Specifically, we ask how firms can create products when the corresponding market does not exist.
\end{abstract}

Design/methodology/approach - This paper is based on a longitudinal study of a high-tech firm, combined with analysis of existing theory in Product Design and Entrepreneurship.

Findings - Markets and products are usually a defining choice made early on by firms in their strategic process. Such a choice guides their development by providing a 'stable concept' to which decisions can be related to. When markets do not exist yet, however, this approach is not effective: Early choice of products and markets limits firms' flexibility by constraining their ability and willingness to adapt, while fundamental new technical and market information is likely to emerge during the project that will prove the initial assumptions wrong.

We show an alternative approach where products and markets actually result from a generic process of products and markets exploration driven by the firm. We suggest that this approach forms a robust design in that it allows the firm to deal with the uncertainty by simultaneously developing its products and exploring markets, while preserving the flexibility to adapt to the changing environment.

Practical implications - The practical implication of this paper is to suggest an alternative approach to deliberate planning in high-tech ventures. With this approach, rather than markets and products, strategy defines a market and technology exploration process.

Originality/value - The paper is original in three ways: 1) It links the product design and market exploration processes in high-tech firm development; 2) It is based on an in-depth longitudinal study; and 3) It results from an academic-practitioner collaborative work.

Keywords New Product Development, uncertainty, high-technology venture

Paper type Research paper

\section{INTRODUCTION}

The purpose of this study is to examine how firms deal with a situation of true, "Knightian" (Knight, 1921) uncertainty that characterizes emerging or disruptive environments. Using an in-depth case study approach, we seek to understand how the firm evolves from an initial situation of uncertainty about its potential markets and products to a situation where an opportunity has been defined and the corresponding products are created.

The choice of products and markets are both essential components of a firm's strategy (Grant, 1995). It is thought that these provide stability that will guide the firm's development, and possibly define its identity. The early and appropriate definition of these strategic components, even before the firm's creation, is assumed to be an important success factor, as exemplified by the institutional importance given to business planning (Honig, 2004). Underpinning this assumption is the predominant use of causal rationality in 
management. Causal rationality assumes pre-determined and well-structured ends, and formulates the decision problem as one of discovering the best possible means to achieve those ends. Causal reasoning proceeds inward by breaking given goals into sub-goals and sub-sub-goals to specific individual tasks (Sarasvathy and Kotha, 2004). Causal rationality, with its emphasis on maximizing expected return or minimizing expected costs and avoiding surprises through accurate prediction and comprehensive competitive analysis, has long served as the normative foundation for both research and pedagogy in business management. It implies the definition of a clear goal, and works with a logic of optimization; i.e., given a particular goal, what is the optimal way (in terms of resources) to reach it.

High-tech firms, however, seek opportunities in disruptive contexts where neither their products nor the corresponding market generally exist at the time of the disruption. In this context, goals cannot be defined easily, markets cannot guide product development, and causal rationality does not work anymore. How can firms create products when the corresponding market does not exist?

We organize the paper as follows. We first highlight and discuss the core concepts of entrepreneurship and product design relevant to our issue. Following this discussion, we describe our methodology and then report on our findings. We then discuss those findings and draw their managerial implications for high-tech venture management.

\section{THEORETICAL BACKGROUND}

To characterize the disruptive contexts in which high-tech firms operate, Knight (1921) distinguished between risk and uncertainty using the concepts of probability. Risk consists of a future with a known distribution, or a distribution that can be estimated by studying events over time. For instance, in the case of a box with six red balls and six blue ones the probability of a particular color being drawn (an event) is perfectly known. On the contrary, "Knightian" uncertainty consists of a future whose distribution is not only unknown, but objectively unknowable. The key difference between Knightian uncertainty and risk is that Knightian uncertainty involves dealing with a future that has no discernible distribution whatsoever, not even in theory. In this case, therefore, neither the calculus of a priori probability nor techniques of statistical estimation can work (Sarasvathy and Kotha, 2004), because the involved objects do not exist yet. To reuse the box example, we do not know whether there is a box, how many balls there are, and the concepts of box and balls might even not be defined. For instance, key elements of the Internet were invented in the late sixties, and commercial application only became significant in the early nineties (Slater, 2002). Such applications were totally unanticipated by the original inventors of the technology: they designed the Internet for military use, ie to provide a secure communication network in case of nuclear war; it is now used for rather different applications such as book buying, television watching, music distribution and game playing.

While firms in established industries (e.g. banks, insurance companies) face risk, those in emerging industries face Knightian uncertainty. They trade in a context where prediction is impossible (Knight, 1921), goals are not predetermined (March, 1982), and the environment does not independently 
select the outcomes (Weick, 1979). Early choice of products and markets, in such a context, limits firms' flexibility by constraining their ability and willingness to adapt (Bhide, 1994; Fredrickson and Acquinto, 1989); as a result, firms are particularly sensitive to disruptions and turbulence and every discontinuity generates an erratic trajectory.

Sarasvathy (2001) studied how entrepreneurs deal with a situation of Knightian uncertainty. She showed that they inverted the principles of causal reasoning and that the inversions together constituted a comprehensive new logic that she calls "Effectuation". Effectuation is a sequence of non-predictive strategies in dynamic problem solving that is primarily means-driven, where goals emerge as a consequence of stakeholder commitments rather than vice versa. An alternative to causal (predictive) rationality, effectuation suggests that "Knightian" actors succeed by taking a progressive approach to the definition of their products and markets (Wiltbank, Dew, Read and Sarasvathy, 2006). What matters, therefore, is not which products and markets they choose ex-ante, but how, in the absence of current markets for future products, such products get created by the firm (Shane and Venkataraman, 2000) and how this process allows the firm to resolve the Knightian uncertainty.

Traditional models for product development projects have emerged from observations in relatively mature, industrial environments, such as the automobile industry (e.g. Wheelwright and Clark, 1992). Their focus is on developing a structured process with clearly defined and sequential phases for the development project through which the future product is defined, transferred to manufacturing, and rolled out to the market (Iansiti, 1995). Those models imply a clear separation between concept development, specification definition, and implementation. Underlying them is the assumption that products are developed in order to serve markets that already exist and have been selected by the firm. As such they adopt a causal logic and tend to pose the problems in terms of optimization. They work well in environments in which technology, product features and competitive requirements are predictable, and no new information is expected that would significantly change the specifications.

In Knightian uncertainty, however, markets do not exist yet, and fundamental new technical and market information is likely to emerge during the project. Uncertainty is such that even the product concept itself can be modified, or even changed completely. For instance, RealNetworks, the current leader in media streaming technology over the Internet, started out as a project to create a TV channel (Sarasvathy and Kotha, 2004). In this context, the success factor shifts from the capability for optimized project execution to the capability to react to new information during the course of the project by changing the product specifications (Brown and Eisenhardt, 1995; Iansiti, 1995), possibly to a large extent. To model the exploratory nature of the design process in such environments, and the blurring of the distinction between the specification and implementation phases, Hatchuel and Weil (2002) introduced the ConceptKnowledge (CK) design theory. CK is based on the articulation of knowledge with the exploration of new products concepts. A unit of knowledge is a proposition with a logical status (true or false). For instance, in designing a car with a platform strategy, a unit might be "The car must use Platform X". A concept is a notion or proposition without a logical status. It is an innovative 
proposition used as a basis for initiating a design project. A “flying boat”, for instance, is neither true, nor false, nor uncertain. The design process starts when unknowns are created by proposing a new concept (going from Knowledge ' $\mathrm{K}$ ' to Concept ' $C$ '). This initial concept is then expanded using properties that have a logical status in $\mathrm{K}$. Concepts are expanded through design spaces, which need existing knowledge, and also generate discoveries and investigation processes that in turn expand the initial concept (Hatchuel, 2006). The design process stops when this dual expansion of concepts and knowledge leads to a concept that can be proved either true or false with the resulting knowledge (flying boat has become a "hydropter"). CK theory is directly applicable in design situations where the work is not based on detailed specifications or a well-identified definition of the object to be designed. It helps the researcher describe the design work not as a deterministic process of optimization, but as a creative exploration, thus meeting one of the design requirements in Knightian uncertainty (Hatchuel and Weil, 2002).

With these core concepts as a starting point, we report empirical findings that suggest how a firm may overcome Knightian uncertainty. Taken together, the findings show that WSoft ${ }^{1}$ succeeded in resolving Knightian uncertainty by defining its stable concept as a generic process of products and markets exploration.

\section{MATERIAL AND METHODS}

\section{Approach}

The paper is based on a longitudinal case study of WSoft, a small European firm developing mobile phone software. We seek to explain how the firm was able to resolve the Knightian uncertainty about its products and markets. Case study research, whether using single or multiple cases, has not only been used effectively for descriptive and exploratory purposes, but also for explanatory purposes including frame-breaking causal inferences about complex and important phenomena (Sarasvathy and Kotha, 2004). As opposed to statistical generalization, case study research allows analytical generalizations (Yin, 2003).

This study contributes to the integration of concepts and theories by using the extended case method, which aims to integrate and synthesize existing bodies of work. In contrast to the Grounded Theory approach (Glaser and Strauss, 1967), the primary focus of the extended case study is not to build new theory. Rather, its method is to integrate and extend existing theories through an iterative process of traveling back and forth between the data, pertinent literature and emerging theory (Danneels, 2002). Specifically, we seek to integrate the entrepreneurial theory of opportunity and the product development theory in the context of emerging markets.

As with any idiographic research, we recognize that the entrepreneurial processes that WSoft employed can be unique and that such processes may be difficult to identify and measure. In such cases, it is the generative mechanisms or underlying processes that are generalizable and not the unique phenomena described (Tsoukas, 1989). The challenge here, therefore, is in identifying these

\footnotetext{
${ }^{1}$ Name disguised
} 
processes, and the drivers of such processes, in the creation and early market development of WSoft.

\section{Choice of firm}

We chose this firm as a case study because, as a player in the market for mobile phone software, it exemplifies the phenomenon of interest. The mobile phone industry is characterized by rapid and unpredictable evolution: pioneers have exited the market (e.g. Alcatel, Siemens, Philips), merged (e.g. Ericsson), or are currently in difficulties (e.g. Motorola). Asian competitors, once poised to overtake them, have had various degrees of success: while Korea's Samsung has become the second largest manufacturer worldwide in just a few years, Taiwan's BenQ's attempt has failed and the company has since exited the market. The industry is also characterized by high profile industry-wide product failures, such as the WAP mobile Internet in 2001, and unexpected successes such as text messaging. Repeated disruptions threaten to undermine the position of actors who cannot react fast enough. For instance, Nokia's leading position was compromised when the company failed to anticipate the sudden popularity of clam-shell phones or of the camera feature in 2003. While the origin of the mobile phone industry can be traced back to the 1970s, it is still undergoing significant disruptions, and as such is typical of a situation of Knightian uncertainty. It is in this context that WSoft attempts to develop its products and markets, and establish itself as leader. While this leadership position is not yet reached, and may not be reached, the firm has successfully dealt with a situation of Knightian uncertainty: it is growing profitably and is recognized as a key player, having won designs with important clients in its field.

\section{Data collection}

Data was collected through a two-year full-time presence in the company. Our primary source of data was the cofounder and CEO of the firm, who is part of the research team as a reflective practitioner (Schön, 1983) and a co-author of this article. Other sources of data were: 1) interviews with other founders of the firm; 2) accounts of actions provided by the firm in the form of press releases; 3 ) analysis of internal reports as well as emails exchanged during the studied period; and 4) analysts' reports (both on firm and industry) whenever available.

To gather industry related background information, we relied on multiple sources such as news.com and telecoms.com, online industry trade magazines, as well as electronic databases of press articles such as Factiva.

As typical in inductive research (Eisenhardt, 1989), the data collected from these multiple sources served as the basis for our own detailed case study on the mobile software industry and WSoft's role in it. To establish the validity of the reconstruction process, we compared our case history with studies in close fields of the software industry, such as Sarasvathy and Kotha's (2004) study of RealNetworks, Cusumano and Yoffie's (1998) study of Netscape, as well as Battelle's (2005) study of Google. We used the case histories (our own and others) to identify the product and market related actions taken by the firm, and to create tables to organize this data chronologically.

These different sources enabled us to examine the data from multiple vantage points (Glaser and Strauss, 1967) and triangulate facts and inferences. For example, press releases provide detailed information on entrepreneurial actions, 
often including top managers' vision of the market and expected consequences of these actions. However, analysis of press releases was limited: they tend to emphasize the positive aspects of the various actions (Rindova and Kotha, 2001), and it was not possible to supplement the analysis with media reports examining the same actions owing to the limited visibility of the firm at that time.

\section{Analysis}

Our unit of analysis consisted of the decision-events that occurred in the creation of the firm pertaining to technology, products and markets choices. We performed a process trace of the decision-events as they occurred, using the event listing method prescribed by Miles and Huberman (1994). We began by listing the decision-events in their chronological order and then examining the relations between product-related, technology-related and market-related decision-events.

We then performed a trace of the domain-knowledge explored by the firm as such decision-events occurred. Such tracing allowed us to examine the role of learning in the development of the firm in relation to these decision-events.

As typical in qualitative research, the validity of our insights was checked with senior executives of the firm as well as with other academic members of the research team.

\section{RESULTS}

\section{Products and markets do not define the stable concept}

Most companies start with an initial target market or product, and WSoft is no exception. Starting in 1998, WSoft's initial business idea was to provide IT services in the field of Web sites development. One year later, trying to get into the product business, the firm initiated a project called $\mathrm{SH}$ aimed at creating an inter-personal communication platform over the Internet. The firm tried, but failed, to raise money for $\mathrm{SH}$, and the project was discontinued. In early 2000, the firm got a contract to develop mobile phones services (using the WAP standard) for a large mobile operator, entering the mobile market for the first time. Based on this experience, and switching back to the product business, it developed a WAP simulator that was sold, with moderate success, to a few wireless operators. In 2002, this simulator was extended and transformed into a browser, and ported to personal digital assistants (PDA). The idea was to use it to develop mobile access to corporate information systems. WSoft would work with IT services providers who would sell the product to their corporate clients. However, the market didn't take off in large part due to the lack of maturity of mobile communication at that time, and the firm exited the market. The browser was then adapted to fit onto a mobile phone, to target mobile phone manufacturers. Despite a certain interest, the product was sold only to a few clients. In 2003, however, upon a client's suggestion, it was further transformed into a user interface engine. Introduced in 2004, the new product has since been successful, and the firm is now growing profitably.

During the period, the firm's products and markets changed radically several times, yet the firm remained the same in the sense that its key constituents didn't change. Its business model, defined as the development and licensing of 
software, didn't change. Its management and shareholding didn't change. Its employee turnover was nil, and the firm didn't experience any traumatic change or crisis. Neither markets nor products, therefore, can adequately define the "stable concept" of the firm, which must therefore be defined differently.

\section{The evolution of products and markets was not random}

Was there, indeed, a stable concept besides the structure itself? The firm's trajectory might have been purely chaotic, with markets and products being randomly tested out. Upon close examination, however, the changes in markets and products clearly did not appear as random; the evolution of the firm followed an iterative, path-dependent process contingent upon (1) relationships forged by the firm, (2) the firm's product development thrust, and (3) its environment. For instance, the WAP contract was obtained for reasons falling into these categories. Firstly, the management happened to know the client's project manager. Secondly, the firm could claim it did know the technology, which it had learned with the $\mathrm{SH}$ project which played the role of complementary asset (Tripsas, 1997) (i.e. an asset whose development had not been considered a priority but whose importance suddenly rose upon a change in the firm's context) and such competences were scarce at the time, and larger, established service providers were too slow to react. Thirdly, the client was in a hurry. The importance of the firm's product development thrust is exemplified by how the market for the user interface engine came about. The firm had been trying to sell its mobile phone browser with limited success for some time when a client suggested that the technology could be adapted to create a user interface (UI) engine. User interface had become a major headache for manufacturers as phones were becoming more and more sophisticated, and such engine could well provide a solution to this growing issue. Within six months, WSoft was able to transform the browser to that effect and begin addressing this opportunity with the resulting new product.

More generally, our analysis of the firm's chronology of decision-events shows that each product/service and market iteration was possible because it was in some way connected to the existing trajectory, thus allowing a trajectory of cumulative learning.

A simplified, high-level version of the chronology of action-events is shown in Figure 1. The firm started out as a provider of development services. It first focused on Web applications, then moved into the related field of mobile Web applications. It then used its newly acquired knowledge to create a mobile Web browser using the Java technology. This product was adapted for several platforms ending on a mobile phone. Another iteration transformed it into a UI engine, and a final iteration consisted into rewriting it from the Java programming language into $\mathrm{C}$.

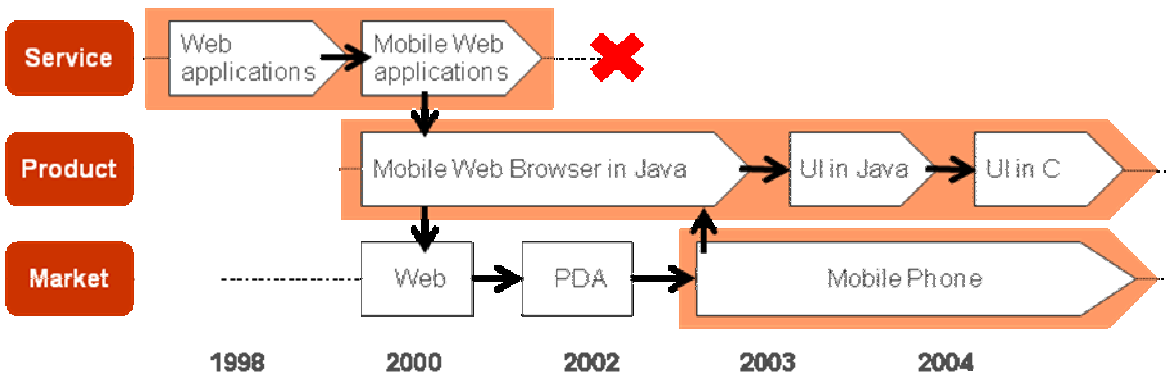


The fact that (1) neither products nor markets can adequately define the 'stable concept' of the firm; and (2) the evolution of the firm's products and markets was not random, but driven by an iterative path-dependent learning process, this suggests that the firm defined its stable concept as a generic process of product and market exploration. This begs the following question to be asked: how does product design theory relate to this proposition?

\section{Market exploration and product development based on lineage management}

Complex software such as that for mobile phones takes months, sometimes years to develop. How was the firm able to drive this development while not knowing in advance which markets it would target? We observed that the last product the firm developed from scratch was the WAP simulator introduced in 2000, seven years ago. All of the firm's subsequent products derived from it, as illustrated in Figure 2.

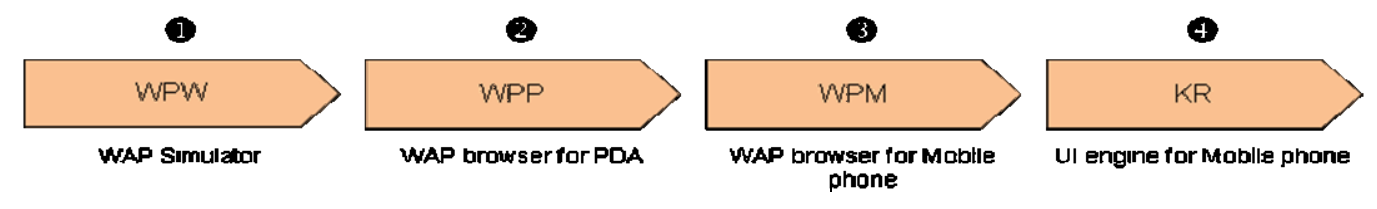

Figure 2. Succession of products

While today's user interface engine for mobile phones (Product KR) and the initial simulator (WPW) have nothing in common, we created a CK (Hatchuel and Weil, 2002) reconstitution of the design history which shows that the evolution followed an iterative, path-dependent process, from one product concept to another, always with a strong common technological base between the two. An extract of this reconstitution, describing the transition from WPM to KR (step 3 to 4), is shown in Figure 3. 


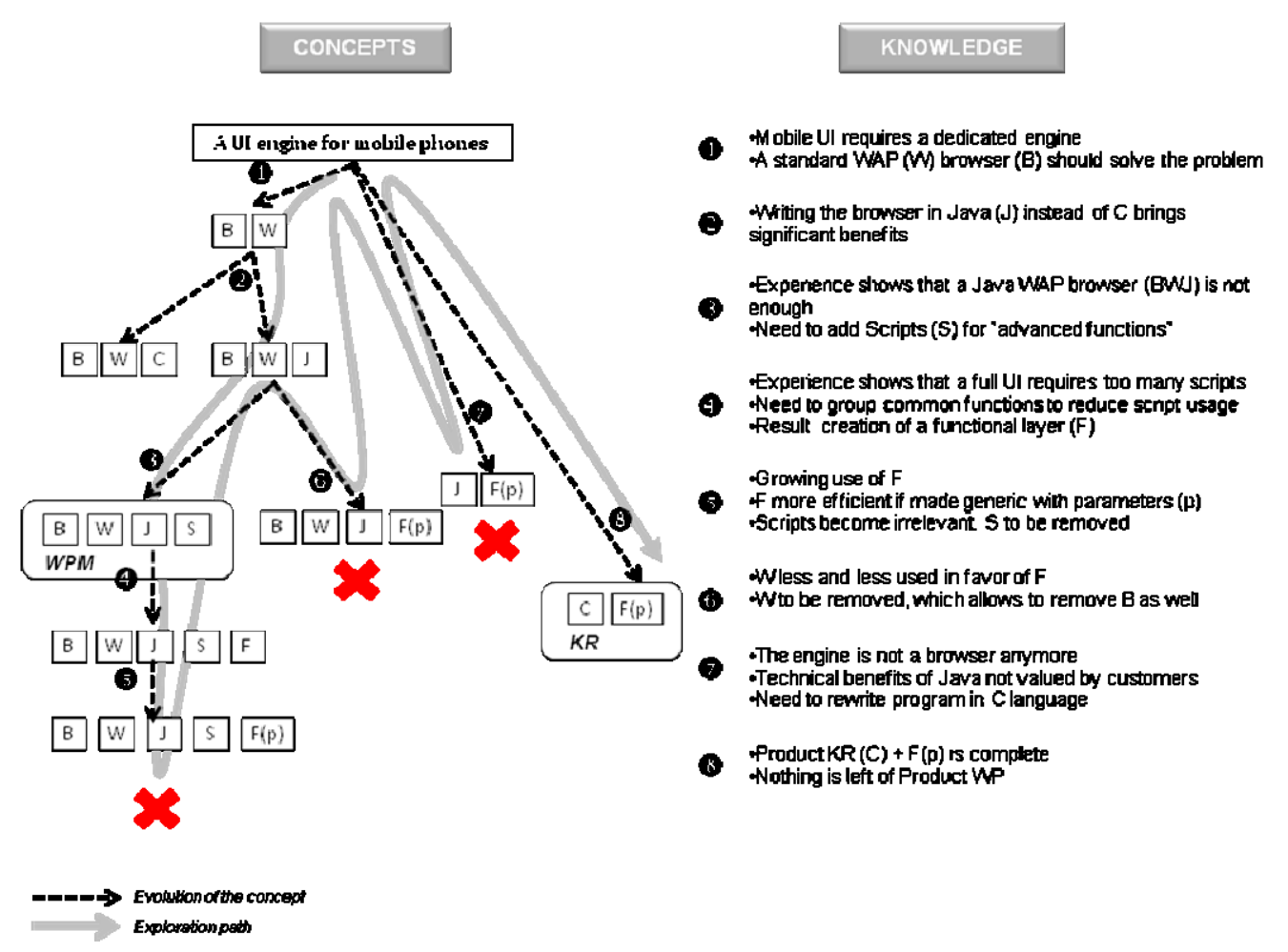

Figure 3. Reconstitution of Product Design history, from product concept WPM to product concept KR

As Figure 3 shows, there is a constant exchange from $\mathrm{C}$ to $\mathrm{K}$ and $\mathrm{K}$ to $\mathrm{C}$ back and forth. Different types of knowledge are used (return from experience, market related and technical/design expertise) to every single logical component of the initial product, thus allowing a continuous progress from one product concept to another. We start from the concept: "A UI engine for mobile phones" (other approaches are possible to address the UI need), try a solution along one branch, backtrack, explore another branch, etc. until we have completely defined what "A UI engine for mobile phones" means in terms of knowledge: a functional layer using parameters and developed in the $C$ language. In between, a series of intermediary products have been tried out, including the product WPM. KR, the end-product, is the result of this exploration.

This sequence of products constitutes a lineage (Hatchuel and Weil, 1999), i.e. an evolving asset that provides both continuity and variation to the design process. Lineage management helped the firm drive the exploration in technology and customer needs on one side, and organize value-creating reuse of acquired knowledge on the other side. The trajectory of domain-knowledge explored by the firm, from its inception to the existing product-market, is depicted in Figure 4. Four main domains are distinguished: platform (for which WSoft creates products), customer, Field (the actual business problem solved by WSoft's product or service), and Technology (that needs to be mastered to address the business problem). Mapping the evolution of products with these domains shows the continuity of the process and the gradual stabilization of the domains, which stop changing. The first to be set is the platform, which is defined when WSoft focuses on embedded systems. Then comes the type of customer (mobile phones manufacturers), then the field (User Interface) and 
finally the technology, when the product is rewritten from the Java to the $\mathrm{C}$ language.

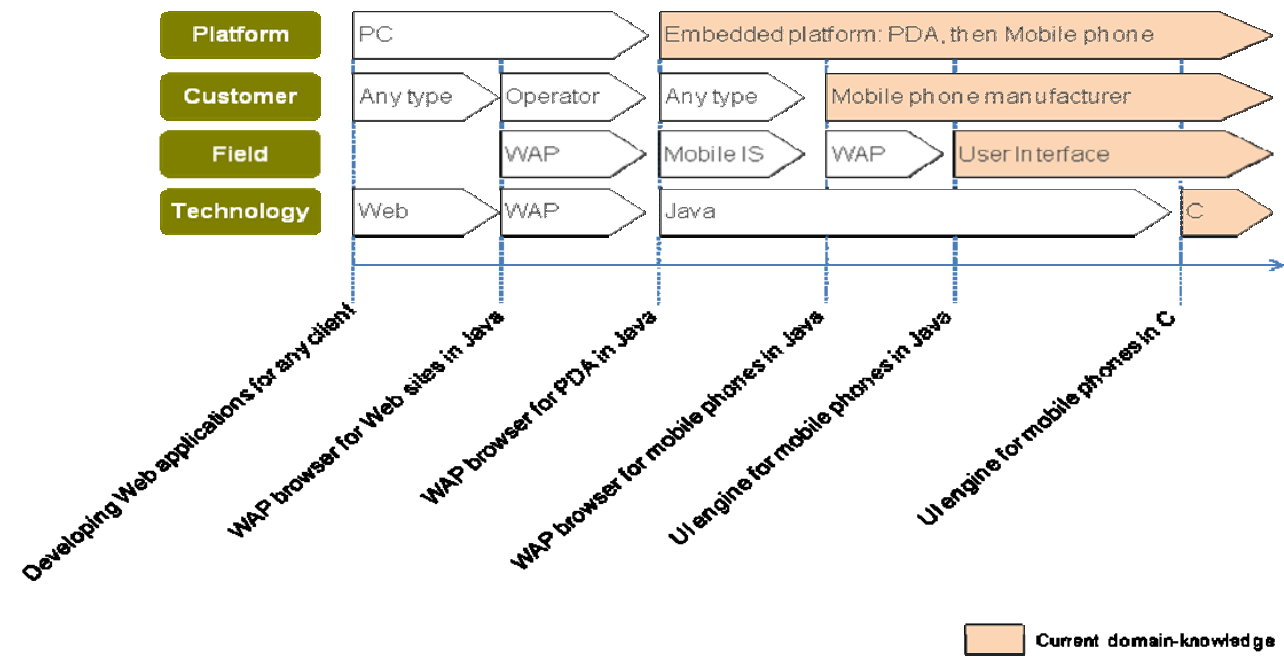

Figure 4. Domain-knowledge explored by the firm

When an opportunity was identified, instead of creating a product from scratch, which would have taken too long and de facto exclude the firm from this opportunity, the current product went through another iteration, leveraging hitherto accumulated knowledge. The technological solution embodied the learning and allowed the business concept to function.

\section{DISCUSSION}

The purpose of this study was to understand how high-tech firms deal with a situation of true, Knightian uncertainty about their potential products and markets. We studied a wireless software firm that was successful in its attempt. The study highlighted three factors that we believe contributed to this success. Firstly, the firm did not define its stable concept in terms of products and markets. Secondly, this did not mean that the evolution of products and markets was random, but rather path-dependent based on cumulative learning, the result of an organized exploration. Thirdly, the exploration of markets and the products development were based on lineage management, reflecting the strategic importance of product design in the firm's strategy.

\section{Lineage-based strategy for startup development}

Product innovation has long been shown to drive learning about customers and technologies (Maidique and Zirger, 1985). Underpinning the firm's concept is a product design strategy relying on a generic technical solution evolving as a lineage that provides both continuity and variation to the design process. The continuity reflects the cumulative learning of previous iterations, while the variation allows local explorations. It was not, however, just a case of technology-push development process as is so common in technology ventures. The CK reconstitution of design and market trajectory shows a simultaneous process of products and markets design, in effect a combination of both technology push and market pull (Berthon, Hulbert and Pitt, 1999). The design process allowed the creation of products that supported market exploration, but market exploration fed the design process in return, until both converged to an 
opportunity. This ability to adapt to the evolution of the target market differs from similar concepts such as mass customization, a concept introduced by Davis (1987). Mass customization is an effort to resolve the paradox of combining the ability to adapt a product to each customer while maintaining economies of scale. Mass customization differs at least in two ways with lineage management. Firstly, mass customization is effective in a clearly defined market where the customization accounts for minor differences among customers within an existing segment, such differences being predictable. Put another way, the variation occurs within a finite space defined by a small number of parameters, and all possible variations are perfectly known in advance. Secondly, mass customization is static: instances of the product are customized, but the product itself doesn't change: this is a condition to reap economies of scale. Lineage, on the contrary, involves profound changes in the product itself to allow addressing new and possibly unexpected market needs. Lineage management also differs from the platform approach. Gawer and Cusumano (2001) define a platform as "an evolving system made of independent pieces that can each be innovated upon” (Gawer and Cusumano, 2001). By organizing the ex-ante sharing of given architecture and/or common elements of product or process, the platform embodies the firm's existing knowledge; what is expected from a derivative project is not new knowledge, but economies of scope. A platform is static by definition: while its constituting elements might evolve. The platform approach is therefore not a strategy for exploration learning, but an efficient one for exploitation learning.

By defining the space of concepts within which the market exploration can take place, the iterative, cumulative, and path-dependent lineage-based product design process actually limits the opportunities that the firm can pursue: what can be achieved in terms of new product from an existing technology base with one iteration is necessary limited. While this might seem to be an inconvenience, Moore (1999) showed the benefit of focus in uncertain environments. It limits unnecessary variation and avoids a random walk of products and markets. It supports the effectual approach of development by providing a product basis upon which the firm can base its 'next' effectual iteration.

\section{Robust design through second order competencies}

As noted by Teece, Pisano et al. (1997), deciding, under significant uncertainty about the future states of the world, which paths to commit to and when to change paths is the central strategic problem confronting the firm. While technological and customer competences can be thought of as first-order competences, the ability to identify, evaluate, and incorporate new technological and/or customer competences into the firm (i.e. a competence at explorative learning and design by exploring and designing new markets or new technology can be thought of as a second order competence (Collis, 1994)). Second order competences enable a company to renew itself through building new first-order competences related to technologies and markets (Danneels, 2002). They provide flexibility and allow cumulative learning. The definition of the stable business concept in terms of second order competences allows to simultaneously explore markets to create value with the generic technical solution, and learn from the exploration in terms of markets and products. It 
forms the basis of a "robust design" (Hargadon and Douglas, 2001) of the firm, defined as the ability to simultaneously make advances while preserving the flexibility to respond to new situations.

\section{Surviving Knightian uncertainty}

This 'robust' approach allows the firm to solve the problem of Knightian uncertainty because it combines exploration and exploitation (March, 1991). The general model of strategy process is that of an initial period of exploration, often before the firm's creation, which ends up when an opportunity is identified, after which the firm turns to exploitation based on previously capitalized knowledge on products and markets. Firms such as Netscape (Cusumano and Yoffie, 1998) or Google (Battelle, 2005) are typical of such approach. In our case, however, explorative learning is not limited to the initial phase, but constant in the development of the firm. This learning process is structured in terms of reuse and leveraging of existing knowledge and competencies into revenue generating products on the one hand, and prudential exploration of new markets opportunities and technology development on the other. Knightian contexts are characterized by complete uncertainty about products and markets. In those contexts, the role of exploration is crucial. Developing customer and technology competences, and then exploiting them, is not enough. Envisioned markets might not come about. New products might fail. New opportunities might emerge unexpectedly that could alter the productmarket pair of the firm. Exploration results in greater ability to adapt to changes, and thus supports future viability (Danneels, 2002). While exploitation provides vital short-term resources, exploration enhances the adaptation of the organization to a changing environment because it increases the variance of organizational activities (McGrath, 2001). This suggests that the firm should maintain equilibrium in terms of exploration and exploitation, despite likely institutional pressures from shareholders that call for a switch to exploitation.

More generally, the study suggests that Knightian uncertainty is resolved by the definition of the stable business concept of the firm in terms of product and market exploration. The concept allows an iterative process of technology push and market pull, driven by a deliberate strategy of learning.

\section{Managerial implications}

The practical implication of this paper is to suggest that high-technology firm management might go beyond two traditional oppositions. Firstly, between deliberate and emergent strategies (Mintzberg and Waters, 1985), and secondly, between exploitation and exploration (March, 1991). A deliberate strategy of learning and lineage management is combined with an emergent strategy of market development: markets cannot be anticipated, but they can be created by actively driving a learning and technology development strategy. The articulation between the deliberate and emergent paths is provided by the product design strategy based on lineages. Exploration does not stop at an early stage but is pursued and combined with the exploitation of current products and markets. Rather than markets and products, the overall firm's strategy consists in defining a market and technology exploration process to resolve Knightian uncertainty. 


\section{CONCLUSION}

Firms in disruptive environment have to deal with a situation of true uncertainty about their potential markets and technologies. We asked how firms can create products when the corresponding market does not exist.

This case study suggests that instead of defining the firm in terms of markets or products, a definition as a generic process of learning and organizational development constitutes a robust approach that allows the firm to resolve the uncertainty by simultaneously developing its products and exploring markets, while preserving the flexibility to respond to new situations.

This paper results from a research initiated two years ago on the development mode of high-tech startups. Insight on the relation between the design process and the market exploration has already been gained. While our findings are largely consistent with the recent literature on Product Development and Entrepreneurship, they must be confronted to a larger sample of firms in order to mitigate the issue of contingency. The idea of a second order stable concept was not deliberately defined by WSoft but rather emerged empirically from an initial lack of market and technology success. We think entrepreneurial firms would benefit from having a normative framework from the outset to increase their effectual performance. Future research will aim at creating such framework.

\section{REFERENCES}

Battelle, J. (2005), The Search - How Google and its Rivals Rewrote the Rules of Business and Transformed our Culture, Portfolio, New-York, NY.

Berthon, P., Hulbert, J. M. and Pitt, L. F. (1999), "To Serve or to Create: Strategic Orientations Towards Customers and Innovation", California Management Review, Vol.42 No.1.

Bhide, A. (1994), "How Entrepreneurs Craft Strategies that Work", Harvard Business review, March-Avril.

Brown, S. L. and Eisenhardt, K. M. (1995), "Product Development: Past Research, Present Findings, and Future Directions", Academy of Management Review, Vol.20 No.2, pp. 343-378.

Collis, D. J. (1994), "Research Note: How valuable are organizational capabilities?" Strategic Management Journal, Vol.15, pp. 143-152. Cusumano, M. A. and Yoffie, D. B. (1998), Competing on Internet Time: Lessons from Netscape and its Battle with Microsoft, Touchstone, New-York, NY.

Danneels, E. (2002), "The Dynamics of Product Innovation and Firm Competences", Strategic Management Journal, Vol.23, pp. 1095-1121. Davis, S. M. (1987), Future Perfect, Addison-Wesley, Reading, MA. Eisenhardt, K. M. (1989), "Building Theories from Case Study Research", Academy of Management Review, Vol.14 No.4, pp. 532-550.

Fredrickson, J. and Acquinto, A. (1989), "Inertia and creeping rationality in strategic decision processes", Academy of Management Journal, No.32, pp. 516-542. 
Gawer, A. and Cusumano, M. A. (2001), Platform Leadership, The Free Press, New-York, NY.

Glaser, B. G. and Strauss, A. L. (1967), The Discovery of Grounded Theory:

Strategies for Qualitative Research, Aldine de Gruyter, New-York, NY.

Grant, R. M. (1995), Contemporary strategy analysis, Blackwell Business,

Oxford.

Hargadon, A. B. and Douglas, Y. (2001), "When innovations meet institutions:

Edison and the design of the electric light", Administrative Science Quarterly,

No.46, pp. 476-501.

Hatchuel, A. 2006. Building innovation capabilities: the development of designoriented organizations. In J. Hage and M. Meeus (Eds.), Innovation, Science and institutional change - A research handbook: Oxford University Press.

Hatchuel, A. and Weil, B. 1999. "Design-oriented Organizations: Towards a unified theory of design activities". Paper presented at the 6th International product development management conference, Churchill College, Cambridge, UK.

Hatchuel, A. and Weil, B. 2002. "C-K Theory: Notions and applications of a unified design theory". Paper presented at the Herbert Simon International Conference on "Design Sciences", Lyon (France).

Honig, B. (2004), "Entrepreneurship Education: Toward a Model of Contingency-Based Business Planning", Academy of Management Learning and Education, Vol.3 No.3, pp. 258-273.

Iansiti, M. (1995), "Shooting the Rapids: Managing Product Development in Turbulent Environments", California Management Review, Vol.39 No.1, pp. 37-58.

Knight, F. (1921), Risk, Uncertainty and Profit, University of Chicago Press, Chicago, IL.

Maidique, M. A. and Zirger, B. J. (1985), "The New Product Learning Cycle", Research Policy, Vol.14 No.6, pp. 299-313.

March, J. G. (1982), The technology of foolishness. In J. G. March (Ed.), Ambiguity and Choice in Organizations: pp. 69-81. Bergen, Norway: Universitetsforlaget.

March, J. G. (1991), "Exploration and Exploitation in Organizational Learning", Organization Science, Vol.2, pp. 71-87.

McGrath, R. G. (2001), "Exploratory learning, innovative capacity, and management oversight", Academy of Management Review, Vol.44 No.1, pp. 118-131.

Miles, M. B. and Huberman, A. M. (1994), Qualitative Data Analysis, Sage Publications, Thousand Oaks.

Mintzberg, H. and Waters, J. A. (1985), "Of strategies, deliberate and emergent", Strategic Management Journal, Vol.6, pp. 257-272.

Moore, G. A. (1999), Crossing the chasm, Capstone Publishing Ltd.

Rindova, V. P. and Kotha, S. (2001), "Continuous "Morphing": Competing Through Dynamic Capabilities, Form and Function", Academy of Management Journal, Vol.44 No.6, pp. 1263-1280.

Sarasvathy, S. D. (2001), "Causation and effectuation: toward a theoretical shift from economic inevitability to entrepreneurial contingency", Academy of Management Review, Vol.26 No.2, pp. 243-263. 
Sarasvathy, S. D. and Kotha, S. (2004), Effectuation in the management of Knightian uncertainty: Evidence from the Realnetworks case. In J. Butler (Ed.), Research on Management end Entrepreneurship, Vol. 1: pp. 31-62. Greenwich, CT.

Schön, D. A. (1983), The Reflective Practitioner, Basic Books.

Shane, S. and Venkataraman, S. (2000), "The promise of entrepreneurship as a field of research", Academy of Management Review, Vol.25 No.1, pp. 217-226. Slater, W. F. (2002), Vol. 2007 Internet Society.

Teece, D. J., Pisano, G. and Shuen, A. (1997), "Dynamic capabilities and strategic management", Strategic Management Journal, Vol.18 No.7, pp. 509533.

Tripsas, M. (1997), "Unraveling the process of creative destruction: complementary assets and incumbent survival in the typesetter industry", Strategic Management Journal, No.18, pp. 119-142.

Tsoukas, H. (1989), "The Validity of Idiographic Research Explanations", Academy of Management Review, Vol.14 No.4, pp. 551-561.

Weick, K. E. (1979), The Social Psychology of Organizing, Addison-Wesley, Reading, MA.

Wheelwright, S. C. and Clark, K. B. (1992), Revolutionizing Product

Development, The Free Press, New York, NY.

Wiltbank, R., Dew, N., Read, S. and Sarasvathy, S. D. (2006), "What to do Next? The Case for Non-Predictive Strategy", Strategic Management Journal, Vol.27 No.10, pp. 981-998.

Yin, R. K. (2003), Case Study Research: Design and Methods, Sage

Publications, Thousand Oaks, CA.

About the authors

Philippe Silberzahn is the co-founder and CEO of a high-technology startup. He is also a Research Associate at INSEAD and a PhD student at Ecole Polytechnique in Paris, France. His research interests are management of technology, entrepreneurship, product design and management in uncertainty. E-mail: philippe.silberzahn@polytechnique.edu.

Christophe Midler is director of the Management Research Center (CRG) and Head of the Chair of innovation management at Ecole Polytechnique. He is Doctor Honoris Causa at Umea University, Sweden. His research topics are product development, project and innovation management, in relation with organisational learning theory. Christophe Midler is the corresponding author and can be contacted at: christophe.midler@polytechnique.edu. 